\title{
Pre-print of \\ On Crimes and Punishments in Virtual \\ Worlds: Bots, the failure of punishment and players as moral entrepreneurs
}

\author{
Appeared as \\ De Paoli, S. \& Kerr, A. (2011) 'On Crimes and Punishments in Virtual Worlds: \\ Bots, the failure of punishment and players as moral entrepreneurs' in Ethics and \\ Information Technology. DOI: 10.1007/s10676-011-9281-7 pg 1-15.
}

\begin{abstract}
This paper focuses on the role of punishment as a critical social mechanism for cheating prevention in MMORPGs. The role of punishment is empirically investigated in a case study of the MMORPG Tibia (http://www.tibia.com) and by focusing on the use of bots to cheat. We describe the failure of punishment in Tibia, which is perceived by players as one of the elements facilitating the proliferation of bots. In this process some players act as a moral enterprising group contributing to the reform of the game rules and in particular to the reform of the Tibia punishment system by the game company. In the conclusion we consider the ethical issues raised by our findings and we propose some general reflections on the role of punishment and social mechanisms for the governance of online worlds more generally
\end{abstract}

Keywords: Virtual Worlds, Cheating, Punishment, Rule Enforcement, Moral Entrepreneur

\section{Introduction}

Massively Multiplayer Online Role-Playing Games (MMORPGs) - a specific subset of Online Games - are a distinct phenomenon of the Information Society ${ }^{1}$. MMORPGs are subject to a range of problems that affect both the service providers (i.e. game companies) and the players (ENISA ${ }^{2}$, 2008) and cheating is one of them. In our research we investigate a cheating practice prevalent in MMOPRGs: the use of bots, computer programs used to automate the game and whose use is a violation of MMORPGs legal documents. The consideration driving our work is that certain forms of cheating that are highly detrimental to the game-play and to MMOPRGs as services - like bots - cannot be prevented with purely technological security solutions, such as automatic detection tools. We propose that social control mechanisms should also be harnessed for preventing cheating.

See http://www.mmodata.net for updated statistics about MMOPRGs.

European Network and Information Security Agency. 
In this paper we argue that punishment is a fundamental social mechanism for cheating prevention in MMORPGs. With punishment we mean a penalty or a sanction received for a wrong-doing (e.g. a law violation), which is given by society or by a social group to the wrong-doers (e.g. those who violate the rules). The End User License Agreement (EULA) and other legal documents of a MMORPG (such as the Terms of Service or the Privacy Policies) describe how the player may participate in the game. When players act outside the terms of the EULA (or other documents), the game company reserves the right to punish players (Alemi, 2007). In MMORPGs, the game companies' right to enforce rule violations is based on their dictatorial power over everything in the virtual world which is granted to them by games' legal documents (Castronova, 2005). Further, EULAs and other legal documents are accepted by all players, in the same form, when they create a game account. These documents explain to players that they are entering a game world with other people and that they have to control their behaviour or consequences will follow (Castronova, 2005). Hence, players might expect to see their peers acting inside these rules and to see rules enforced and rule violations punished by game companies when they are severely violated. In this paper we propose a theorization of the social mechanism of punishment in relation with one of its primary functions: the prevention of wrong-doing. In this way we provide recommendations for adopting effective punishments to help prevent cheating in MMORPGs. The theorization we propose is based on the outcomes of an in-depth empirical case study of a major MMORPG.

Our investigative approach is multidimensional. Firstly, we selected a relevant case study - the MMORPG Tibia (http://wWw.tibia.com) that was undergoing crucial changes with regards to the organization of rules enforcement against cheating. Secondly, for the data collection we conducted an ethnography of the virtual world (Nardi, 2010; Hine, 2000). Thirdly, we used an inductive approach for analysing the ethnographic data based on Grounded Theory (Charmaz, 2006). In our bottom-up theory building, and in close relation with our ethnographic method, we used the work by Becker (1963) on the Sociology of Deviance and some contributions from the Sociology of Punishment such as Cragg (1992), Beccaria (1764) and Foucault (1975). We use the conceptualization of punishment by these authors to organize and analyse our data. In particular, the seminal and neat work by Beccaria helped us to conceptualise the potential preventive power of punishment in MMORPGs, 
The paper is organized as follows: we first describe MMORPGs and cheating (section 2); then we present our investigative approach and the case study (section 3-4); we then present the empirical research describing the role of punishment in Tibia (sections 5-7); in the conclusion we consider the ethical issues raised by our findings and propose some general reflections on the role of punishment and social mechanisms for the governance of online worlds more generally

\section{A Short Description of MMORPGs and Cheating}

MMORPGs are both highly sophisticated technological systems (Acterbosch, 2008), as well as 'deeply social' Virtual Worlds (Taylor, 2006; Bainbridge, 2010; Nardi, 2010) in which millions of players interact online through their avatars. Further they are persistent and continue to function even after individual players have logged out. Finally, the business model of well known MMORPGs like World of Warcraft is based on an initial retail sale plus subscriptions fees (Kerr, 2006). More recent MMORPGs offer often free accounts and make their money on microtransactions (e.g. Allods Online ${ }^{3}$ ).

For game players, levelling one's avatar is a key task in MMORPGs. An avatar is the persona that represents and is controlled by the player inside the game. Levelling an avatar is achieved by acquiring and accumulating experience points which are obtained by killing monsters or completing game quests. By increasing the level, the avatar will be able to become more powerful inside the game. Collecting virtual gold is also important as with it avatars can acquire special items such as weapons, gears or in-game commodities. It is important to clarify however that most high-end gears in MMORPGs are not always buyable with gold and can be obtained for instance by completing game quests. Therefore, collecting virtual gold is an important activity in MMORPGs that allows the avatar to buy certain items and commodities, but collecting gold is not usually as central as levelling.

In an MMOPRG there are different forms of rules $^{4}$ that guide the behavior of players. Firstly, we have the design rules of the Virtual World that are encoded in the software artifact (Nardi, 2010): for example avatars might be allowed to enter buildings not only by using doors, but also to walk through walls by drinking a magic potion or casting a spell. Secondly, and most important for us,

\footnotetext{
3 http://en.allods.gpotato.eu/

$4 \quad$ Castronova (2005) and Nardi (2010) contain extensive discussions of rules in MMORPGs. Readers are invited to refer to their books for full discussions of rules in MMORPGs.
} 
we have rules which players must agree with before they enter the game world for the first time. By clicking on the button "I Agree" or "I Accept" of EULAs, players implicitly agree with the rules contained in these documents, even if they did not read them. The acceptance/agreement with these legal documents is mandatory for players, in order to play the game. These rules usually include: the game EULA - protecting the software client, the Terms of Service (ToS) protecting the software running on the server and game rules describing the main forms of rule violations.

Cheating is a key problem affecting MMORPGs and Online Gaming more generally (ENISA, 2008), insofar as it is perceived by the developers, publishers, and many players to be a threat to the social experience and economic viability of a game ${ }^{5}$.

Elsewhere we showed the limits of current mainstream definitions of cheating in MMORPGs and digital games in general (AUTHORS, 2010a) understood as the set of activities that brings the player/cheater an unfair advantage over other players (see Yan and Randell, 2005; Salen and Zimmerman, 2004; Smith, 2004). Cheating, according to standard typologies (Yan and Choi, 2002), includes a variety of activities such as the exploitation of game bugs, the manipulation of other player's trust or the use of software to manipulate the game code. In our view, mainstream definitions of cheating tend to focus almost exclusively on what gives players unfair advantages (e.g. a bug exploitation, a design weakness, the manipulation of game code), whereas everything else related with cheating remains largely unstudied. In contrast we argue for a definition of cheating as the inter-relation of a number of MMOPRGs elements that in themselves do not necessarily bring unfair advantages to cheaters (AUTHORS, 2010a) ${ }^{6}$, including: technologies (game code and infrastructure), legal documents, game play and also the enforcement of rules against cheating. Our working definition of cheating purposefully avoids any a-priori judgment (Latour, 1988) that cheating in MMORPGs is either good or evil. In this way we implicitly agree with the methodological principle of avoiding imposing a predetermined grid of analysis onto our data (Callon, 1986). In particular, our working definition of cheating allows us to avoid deciding beforehand that cheating is something detrimental to the gameplay or something that provides

$5 \quad$ In our literature review on cheating we consider only contributions related with digital and online games, in order to narrow the focus of the review and concentrate our effort on the digital aspects of cheating. We purposefully avoid to discuss contributions addressing cheating "offline", as for instance in DeKoven (1978).

$6 \quad$ This view shares some concepts with Kücklich (2007 and 2009). 
cheaters with unfair advantages, which is something implicitly contained in traditional definitions of cheating in digital games. Our working definition of cheating instead allows us to study the enforcement of cheating rules, something which has rarely been studied so far $^{7}$ from an empirical point of view, given that this issue (i.e. the enforcement) falls outside the traditional definition of cheating as the actions that give players unfair advantages.

On another occasion (AUTHORS, 2010b) we showed that technical literature sees cheating mainly as a technological flaw or weakness in game information security (Yan and Randell, 2005; Di Chen and Maheswaran, 2004; Ferretti and Rocetti, 2006; Smed and Hakkonen, 2006), with hence a technological bias. We also showed that media literature on cheating focuses mostly on cultural aspects $^{8}$, emphasizing players resistance to design choices (Consalvo, 2007; Kücklich, 2007), cheating as a learning process (Fields and Kafai, 2009) or motivations or intentions to cheat (Smith, 2004; Consalvo, 2007). Our approach attempts instead to keep together - in a seamless web - both cultural and technical aspects, following a well established tradition in Science and Technology Studies (Latour, 2005; Bijker, 1995; MacKenzie and Waijcman, 1999). Our approach purposefully avoids any a priori reduction of cheating in MMORPGs to either the technical or the social.

\section{Theorising Punishment}

In this paper we theorize about the role of punishment in the prevention of game rules violations. The concepts proposed by Becker (1963) in his book Outsiders: Studies in the Sociology of Deviance constitute the scaffold of our theory. For Becker (1963, p. 59) deviance is: "a breakdown in social controls which ordinarily operate to maintain the valued forms of behaviour". Deviance is the violation of socially established formal and informal rules and norms.

In our research we focus on a specific rule violation in MMORPGs, the use of bots: software programs that use Artificial Intelligence routines, tailored specifically for the game, to automate the gameplay. Botting ${ }^{9}$ and using macros for automating the game is a violation of MMOPRGs

\footnotetext{
$7 \quad$ Chapter 6 of Consalvo (2007) is an exception which contains a discussion of the anti-cheating industry and the development of anti-cheating tools.

$8 \quad$ This view has recently been criticized also by Withson (2010).

With botting we refer to the act of using a bot. Later in the paper we use the term botter to refer to the user of a bot. These terms follows those used by Tibia players in their discussions.
} 
legal documents ${ }^{10}$. For example in World of Warcraft (WoW) - the most successful and now prototypical MMORPG - using a bot to tamper with the game client is a violation of term $2 \mathrm{~B}$ of the EULA (Blizzard, 2010). In Tibia - our case study - using a bot is a violation of rule 3c (Cipsoft, 2009b), which states that it is forbidden to manipulate the game client or use additional software to play. Using a bot is a breakdown of social control and a violation of the rules that players accept when they create a game account.

Becker argues that any serious study of deviance should account not only for the rules violation but also for the "actions of enforcement of such rules and norms" (Becker, 1963, p. 1):

All social groups make rules and attempt, at some time and under some circumstances, to enforce them. Social rules define situations and the kinds of behavior appropriate to them, specifying some actions as "right" and forbidding others as "wrong".

We maintain that studying rules enforcement against cheating in MMOPRGs is therefore as important as studying cheating as a rule breaking action. Playing without the aid of external software is a behavior that conforms with the rules of MMORPGs, whereas using a bot is a violation of such rules. Further, rules are enforced by the enforcing authority. In MMORPGs, game companies are the enforcement authorities and the material act of enforcement is often delegated to Gamemasters ${ }^{11}$ or sometimes to automatic detection tools (Consalvo, 2007).

For Becker (1963, p. 122) rule enforcement is an enterprising act with someone taking the initiative to create and enforce rules:

First, enforcement of a rule is an enterprising act. Someone - an entrepreneur - must take the initiative in punishing the culprit.

In some parts of his book Becker calls this the Moral Enterprise. Becker explains that (1963, p. 145):

10 Some MMORPGs may tolerate the use of macros and bots, but this is more the exception than the rule. (see Wikipedia Contributors 2010, MMORPGs, bots).

11 Gamemasters are people (often employees of the game companies) that act as moderator or enforcer of the game rules. 
Wherever rules are created and applied, we should be alive to the possible presence of an enterprising individual or group. Their activities can properly be called moral enterprise, for what they are enterprising about is the creation of a new fragment of the moral constitution of society, its code of right and wrong.

The moral enterprise is therefore an entity (an individual or collective actor) that creates fragments of the moral constitution of society: it creates codes of conduct that are meant to be followed by people. Game companies, even if their focus is on business and profit, have also this role of moral enterprising as they, with legal documents, create public rules that should be followed by players and they define what is right and wrong inside the game.

Punishment is a crucial aspect of the moral enterprises attempt to ensure that shared rules are followed by members of a group (Cragg, 1992). Taking inspiration from Foucault (1975) we understand punishment as a situated phenomenon which involves both negative aspects that repress, or exclude, but also positive effects. According to Beccaria (1764, Ch. 01), punishment is a mechanism that society uses to defend public spaces - generated by the social contract - from the usurpation of individuals. Punishments inflicted for the violation of the social contract are accepted by people with the acceptance of the social contract in itself (Rousseau, 1762). Even if an MMORPG EULA cannot be considered as a social contract the dynamics in place are similar to those just described: when players click on buttons such as "'I accept" or "I Agree" of MMORPGs legal documents - even without reading their content - they also implicitly accept the punishments set by the game companies for the rules violations. This happens even if players do not know what these punishments are.

Punishment possesses an important social function: it allows the prevention of wrong-doing against society and social groups:

The end of punishment, therefore, is no other than to prevent the criminal from doing further injury to society, and to prevent others from committing the like offence. (Beccaria, Ch 12) 
This preventive power is why we think punishment should be part of our design of new sociotechnical solutions against cheating as rule violation in MMORPGs: acting preventively is better than punishing afterwards (Beccaria, 1764), when damage has been inflicted on society.

We found it useful in our analysis of the Tibia punishment controversy to use the classical distinction between retributive and forward looking punishments (Cragg, 1992; Bedau and Kelly, 2010).

Retributive punishment can be characterized as follows (Cragg, 1992, p. 15):

1) it is backward-looking. It justifies punishment as a response to a past event;

2) it justifies punishment as a response to an injustice;

3) the offender gains an advantage which he/she does not merit. Punishment removes the undeserved benefit by imposing a penalty to the offender, which restores the social equilibrium $^{12}$. To some extent, punishment balances the harm inflicted by the offence to society.

On the contrary forward looking punishments (Cragg, 1992, p. 31-33):

1) require that punishment be evaluated by reference to the welfare of offenders, victims, and the public at large;

2) seek to influence the behaviour of people through the use of rewards and punishments;

3) should not be inflicted except where some good will come of it.

At a general level, reward and punishment systems are a defining game mechanic of the design of any digital game (Salen and Zimmerman, 2004). In a digital game, basic in-game actions (such as shooting or jumping) are regulated by internal game mechanics. Killing a monster or completing a quest are actions rewarded, for example, with special items. Likewise being killed by a monster or falling down from a platform might result in a punishment such as a decrease in an avatar's level. According to Morrison (2009) "Punishment and Reward Systems nudge the player towards certain behavior. They give meaning and weight to the Base Mechanics, forcing the player to think about their choices" "13. A game's punishment system has the power to make the players reflect on the consequences of their actions and to shape the game experience and player's game actions (Salen and Zimmerman, 2004). Reward and punishment are constraining aspects of the game design, able

12 This principle is called the Balance of Justice Standard.

13 Here the author refers mainly to in-game actions. 
to direct players toward what is right and what is wrong in a game (Sicart, 2009; Johansson, 2009). It is the already central position of punishment in game design that makes this social mechanism a good candidate for preventing cheating in MMORPGs.

\section{The Case Study of Tibia}

Our investigation is based on an in-depth case study of the MMORPG Tibia (http://www.tibia.com), developed and published by the independent company Cipsoft. The game has an estimated player base of 300,000 and around 1.3 million accounts. To create an account in Tibia is free, but players can pay a subscription fee for a premium account and receive additional services, for example more areas of the game to enjoy or special quests. A single Tibia account allows the player to create multiple characters/avatars belonging to that account.

Tibia was selected as case study because an intense anti-cheating strategy was deployed by Cipsoft and on the $5^{\text {th }}$ of January 2009 Cipsoft (2009a) published an article entitled "Where Will Cheaters Go From Here", which described from our point of view a new moral enterprising strategy against the use of bots.

Tibia, like others MMORPGs, has in recent years being affected by the diffusion of bots (see discussions in Hoglund and McGraw, 2008; Consalvo 2009). Common bots in Tibia automate the game so that the bot can play in place of the player. The bot - among other things - does the most common leveling actions which includes controlling the avatar in: moving around on the game map, targeting and killing monsters and looting them. In this way the bot allows a faster leveling of the avatar and extensive virtual gold gathering when compared to purely "manual" play. Using a bot in MMOPRGs is a form of cheating and a rule violation.

Our claim that Cipsoft is 'the moral enterprise' of Tibia is justified by the company policy, described in the Tibia Manual, Section 6 Rule Enforcement, which states:

Tibia, just like the real world, needs laws and rules which clearly show what is allowed and what is not. These rules are called the Tibia Rules. We expect our players to respect and to follow the rules at all times so that a minimum level of fairness is maintained in the community. 
Cipsoft sets rules with the purpose to clearly define what is allowed (what is right) and what is not allowed (what is wrong) in Tibia. Cipsoft is first an economic enterprise focused on maximizing profit, and the game rules defining what is allowed in Tibia attempt to generate a fair game service for all customers. However, Tibia rules create also what, following Becker we can call a fragment of the moral constitution of the MMORPG: Tibia rules attempt to create norms that guide the actions of players inside the game, otherwise no fairness can be maintained by the company inside the Tibia community. Cipsoft is therefore both an economic and a moral enterprise and defines, in the Tibia Manual (Cipsoft, 2010), these rules as a code of conduct that must be followed by players. Using a bot can be conceptualized as a deviant act (according to Becker definition) something against the social norm set by the company - as it is a direct violation of Rule $3 \mathrm{c}$ of the Tibia's code of conduct.

One of the tasks for a moral enterprise is the enforcement of rules. The launch of the new anticheating campaign in January 2009 marked a new enterprising act against the use of bots. This campaign involved the introduction of an automatic tool for bot detection and several mass bans of cheating accounts ${ }^{14}$.

Cipsoft as a moral enterprise has of course its own attitude toward punishment which is intertwined with the business of developing an MMORPG. Cheaters are also customers and the company has a sort of "redemption" attitude toward them (Cipsoft, 2009a):

Let this be the last warning to all cheaters. We do not want you here. The stage is open and we are on:

$$
\begin{aligned}
& \text { It's your choice where you go from here. } \\
& \text { Go the wrong way and we'll be there! } \\
& \text { Or come clean while you still can } \\
& \text { and you may avoid getting a ban. }
\end{aligned}
$$

Take your pick

but take it quick...

\footnotetext{
14 With a ban of more than 100,000 accounts in total and the deletion of 3500 of them. These statistics on deletion $\begin{array}{cccccc}\text { were } & \text { updated } & \text { by } & \text { Cipsoft } & \text { until } & \text { December }\end{array}$ http://www.tibia.com/news/?subtopic=latestnews\&id=1148). Official stats on mass bans are also updated until December 2009 and the number was about 50,000. However further mass-bans have followed during 2010, bringing the number of banned accounts certainly above 100,000 .
} 
The anti-cheating campaign was announced as a last warning for cheaters with an invitation to embrace the "right way". In the statement above we see that Cipsoft has an interest in making all players play fairly rather than deleting cheaters. The problem of revenue is crucial here as the company has a medium-long term plan in which Tibia should become clean from bots and this plan is based on the redemption (come clean while you can) of cheaters.

In this paper we recount some relevant events from the Tibia anti-cheating campaign which occurred during our fieldwork. Our research was not designed to answer a structured research question. Rather, we used an inductive-qualitative approach focused on building a theory as outcome of the research.

We collected data from January 2009 till June 2010 from a number of sources, but mainly from the Tibia Forums ${ }^{15}$ (1485 forum pages composed of 20 posts each) ${ }^{16}$ all related with the new Cipsoft anti-cheating strategy, and from both prior to and after the launch of the campaign. The data collection also included game documents including the Tibia game license, the game rules, the game manual and a number of articles written by Cipsoft prior and during the anti-cheating campaign. Our research also involved playing the game - as a form of participant observation for a number of hours (at least 6 hours a week for the first 6 months of investigation) with two different characters/avatars. Our goal in playing the game was to understand and master the mechanics, rules and vocabulary of the game in order to follow the players discussion on the forums.

We reconstructed the events of the Tibia anti-cheating campaign based largely on the discussions taking place in the game forums which we followed using ethnographic techniques. While not all the Tibia players took part to the discussions, the Tibia forums were quite busy during the period of our investigation with several intense discussions - some lasting for months with hundreds of messages - about the Cipsoft anti-cheating strategy. Several direct communications and discussions on the topic also took place between players and company representatives. Although, we cannot make generalizations for the whole player community, we are confident that our data captures the players contributions and influence on changes in game rules and on the Tibia

15 Tibia Community Forums URL http://forum.tibia.com/forum/?subtopic=communityboards . The forum excerpts we present in the paper can be retrieved - if not deleted by Cipsoft, which systematically removes closed threads - using the post-number provided after each quotation.

16 Data collection and analysis follows the Association of Internet Researcher Ethical Guidelines (Ess and AoIR, 2001). 
punishment system. It is the moral enterprising process coming from players discussing cheating and punishment on the forums that we account for in this work.

All the data collected was analysed using a Grounded Theory (GT) approach (Charmaz, 2006; Strauss and Corbin, 1998) in which theory is built via a set of recursive relationships between the data (thorough coding) and the concepts composing the theory. GT allows the creation of social theory (by an articulation of the concepts) in an inductive way and starting from empirical data.

\section{The Failure of Punishment}

We begin the empirical part of the paper by introducing a concept that we define as the failure of punishment. Beccaria (1764, Ch. 27) argues:

That a punishment may produce the effect required, it is sufficient that the evil it occasions should exceed the good expected from the crime, including in the calculation the certainty of the punishment, and the privation of the expected advantage.

In order to produce its desired effects (i.e. preventing further violation of rules and defending the public space), the punishment should be sufficient to balance the outcomes of the wrong-doing. This should include the removal of the advantages obtained by the wrong-doers. There is therefore a sort of calculation or comparison, done often by the authorities and the public, between the violation of the rules and the punishment one should receive for violating the rules. But, what happens when the punishment is perceived by lay people as being insufficient in comparison to the advantages obtained by violating the rules? And what if there is not enough privation of the expected advantages? The outcome of this failure of punishment - the situation in which the punishment is not sufficient and therefore does not produce the desired effects - is problematic. Expanding on Cragg (1992, pp. 114-115) we consider that there are three problems in the failure of punishment ${ }^{17}$ :

(1) the victims (of a crime/rule violation) have a growing sense of injustice and vulnerability, because the punishment is not able to balance the offence;

17 We do not consider here the issue of compensation to the victims of crime, as this is an aspect which did not emerge clearly from our data. The failure of punishment in our case was not a failure of compensation to individual victims for a singular case of offence, as we are analysing the general case of botting in a game. 
(2) those who violate the rules only obtain benefits from their wrong-doing as punishments are too mild in comparison with the offence caused to society;

(3) there is a loss of confidence in the ability of the moral enterprise to ensure that rules are followed.

Our examination of the Tibia case study and the failure of punishment will centre around the above three issues, with a focus on considering players as the direct victims of cheating as it is them who suffer from the disruption of the game balance caused by the proliferation of bots. Cheating in an MMORPGs, because it involves necessarily interactions with other players (differently from traditional single player games), is also a moral offence toward these other players and something that should be remedied when necessary (Kimppa and Bissett, 2005).

A good starting point for our discussion is a huge discussion thread ${ }^{18}$ entitled Delete Botters launched by a Tibia player $\left(\right.$ Shelbz $\left.^{19}\right)$ on January 2008 on the "Tibia Proposal Forum", 1 year prior to the CipSoft anti-cheating campaign.

Shelbz, in particular, criticized Cipsoft's attitude toward botting and was looking for support from the player community for a new strategy against bots. Here is an excerpt from the opening message of the thread:

Why should cheaters who ruin the game play, economy of servers, atmosphere and attitudes of all players be given anything more?

The idea of "crippling" botters is worthless. Botters should not be able to continue to use their characters in any way shape or form. Tibia as a whole must not devolve any further to accommodate cheaters. ${ }^{20}$

This thread starts a public discussion of rule violation (the use of bots) with the claim that botters seriously harm the social space of the game and hence their use should not be tolerated. In this situation, argues Shelbz, deletion from the game is what botters deserve. In his book Becker (1963) noted that when violations exceed a threshold of tolerance we can expect the public to exercise

\footnotetext{
18 See http://forum.tibia.com/forum/?action=thread\&threadid=1978162

19 Shelbz is the name the player used to post on Tibia forums.

20 Posts to the forums contain many errors. We avoided using sic for identifying mistakes and presented them as they were.
} 
pressure on the moral enterprise (Becker, 1963; Cragg, 1992) for a solution to the problem. Not that the violation was ignored by Cipsoft but rather, according to Shelbz, the actual punishment was insufficient. At the time of this discussion, the rule enforcement for the whole Tibia (including rule $3 \mathrm{c}$ ) was delegated to a limited number of volunteer gamemasters ${ }^{21}$ who could not deal with everything happening over the 70 Tibia servers ${ }^{22}$. Further, the punishment for using a bot in violation of Tibia rule $3 \mathrm{c}$, was a temporary account banishment ( 1 month ban) with a further temporary final warning (criminal record) lasting for 6 months and reminding players that any further rule violation would lead to a deletion of the account ${ }^{23}$. After the expiration of the warning the account becomes fully clean again. To clarify, the key difference between banning and deleting an account is that in the first case the player cannot play with her account for a given period of time, the account is in fact temporary blocked. But after the ban period has passed the account becomes fully available again. Deletion, instead, means that the account cannot be used anymore to play and the account in itself is not anymore available or visible to the player or to the player community at large.

In any case, the punishment against cheating ( 1 month ban + temporary criminal record) was seen as not enough by Shelbz who launched the Delete Botters thread. Shelbz found support from many in the Tibia community ${ }^{24}$ who requested that the punishment system be reformed including an instant deletion of those accounts caught using a bot.

The anti-cheating campaign launched by Cipsoft in January 2009 is an important moral enterprising act against bots. However this campaign, for quite some time, focused mostly on improving the detection of rules violations (i.e. acting after the violation), especially with the introduction of an automatic tool for detecting bots. The existence of an anti-cheating tool was first revealed by Cipsoft together with a first mass ban (of about 5000 accounts) at the end of January 2009. Over Tibia forums players warmly welcomed the new actions that partly restored players' faith in the ability of Cipsoft to deal with the problem of botting:

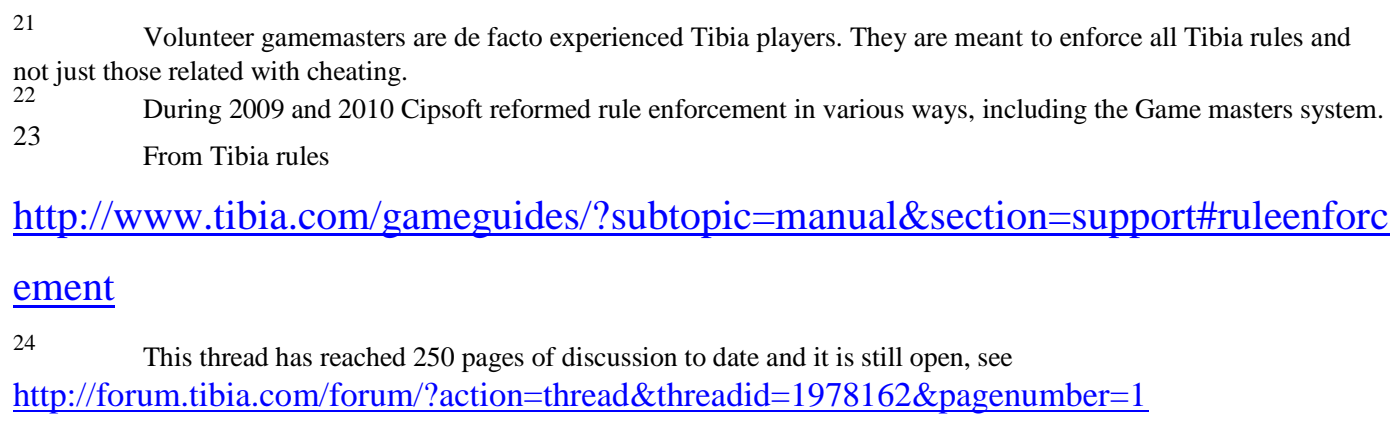


Way to go Cipsoft, you bring hope to all the honest players and you finally show that you care what happens to Tibia and that you will try to change negative direction it was doomed to end. [Character Nienna Telperin, 30/01/2009, Post \#22040452]

However, nothing overt was done in terms of punishment by Cipsoft and in fact the sense of injustice expressed by Shelbz for the inadequacy of existing punishments was still present on the forums until the beginning of 2010 when a reform of punishment took place (see section 7).

\subsection{Growing sense of injustice about inadequate punishment}

One of the elements giving birth to a sense of injustice and vulnerability related with the failure of punishment is the consideration that fair players are disadvantaged compared to botters in playing the game. Based on our analysis of forums we observed a strong perception from players posting in these forums that those who violate the rules have, in the end, more advantages compared to those who behave according to the rules. For players, current punishment ( 1 month ban +6 months warning) does not seem to be proportional to the unfair advantages obtained by cheaters. For a number of players posting on forums, in other words, there were definitely more advantages to be a botter, rather than being a fair player, as the following analogies with the real world well explains:

So after 30 days, these "players" will be allowed to come back and have everything they DIDN'T work for still be there for them? Do you see people who steal things or cheat for things irl ${ }^{25}$ (and get caught and punished for it) still be able to keep any of what they stole or cheated for?.. Absolutely not!

[Character Sinzar, 14/01/2009, Post \#21849387]

This is like someone robbing a bank and getting a few million dollars, then he has to go to jail for a month and when he's out he gets to keep the money. What kind of nonsense is that?

[Character Despen, 23/01/2010Post \#26294884]

$25 \quad$ Irl - in real life. 
After a ban of 30 days those who have violated the rules come back keeping what they have unfairly obtained, such as levels and gold. As we can see the idea that fair players are disadvantaged is clearly linked with the proportionality of punishment. The actual punishment (30 days ban) is considered too lenient to balance the unfair advantages obtained by using bots:

it's also absolutely evident that unless botters lose what they get cheating they will continue to do so. I can't beleive that you haven't take the decision yet to harden cheaters punishment like losing levels/Skills, permanent criminal records etc.

[Character Akua Knight Of Dark Elf, 18/02/2009, Post \#22243229]

The actual punishment does not affect the unfairly obtained advantages. There is not, to use Beccaria own words, any "privation of the expected advantages" and hence one of the elements of a successful preventive punishment is not fulfilled by current Tibia punishment. There is, in this way, a problem of competition: levels, skills and gold unfairly obtained remain with the character after the punishment has been carried out. It is therefore not a surprise that fair players posting on forums feel a sense of injustice, because of the failure of current punishment.

In brief, the social mechanism of punishment whose goal is to restore the imbalance committed by wrong-doers toward 'society', as well as facilitate the prevention of wrong-doing, here is not effective for preventing cheating.

There is a downside related with the failure of punishment in Tibia: wrong-doers are not afraid of being punished for their actions. This is at least the perception expressed on forums by fair players:

Cheaters are not afraid at all and $i$ have to watch them day by day all month long hoping that mass ban maybe catch one of them. They even did not lose money and exp they got in unfair way. [Character Eriea, 25/05/2009, Post \#23545396]

We see how a sense of injustice increases with the players witnessing that botters are not punished: cheaters are seen as acting with impunity. 
Given that being a botter is perceived to be a great advantage and that the punishment seems to be mild compared to the offence, fair players might feel compelled to turn themselves into botters. This feeling is acknowledged by CipSoft (2009a):

Finally, the motivation of many cheaters is to oppress other players which ultimately leads to more fair players leaving Tibia and more cheaters coming and even worsening the situation. This also includes those players who are fair in their heart but who feel that their only chance to keep up with the cheaters is to start cheating themselves.

In order to keep up with cheaters, fair players feel that becoming cheaters is a viable option. The failure of punishment brings about this paradoxical situation, which is often expressed on forums:

Most people turn to bots because they have no choice. The advantages of botting are so high. Legit people can't keep up with botters. They are left behind. FAR behind... So they turn to bots just purely because they need to keep up with the other botters.

[Character Yuki Zou, 23/10/2008, Post \#20911261]

In conclusion, the failure of punishment means that even fair players are pushed to violate rules in order to survive and compete within the game.

\subsection{Loss of confidence in the Moral Enterprise}

The failure of punishment leads to a further consequence for players: a loss of confidence in the ability of the company to fulfill its role as moral enterprise:

When the punishments are only 30 days I feel I have been abandoned by $C I P^{26}$ and that they are more concerned with their bot accounts being happy.

[Character Sir Duckie, 06/05/2009 Post \#23295784]

26 CIP stand for Cipsoft 
When punishments are not effective in counteracting wrong-doing, then rule violation becomes an accepted behaviour. This is common, as noticed by Cragg (1992), in those situations in which rule violations are not pursued and punished enough. There are however understandable reasons why Cipsoft is acting softly toward botters:

Well, $i$ agree with the thread, but $i$ dont think CipSoft will do anything against botters since they are the ones that buy premium accounts every time so they are the better customers.

[Character Sir Baldek, 25/07/2008, Post \#19719626]

According to players posting on the forums botters pay for premium accounts. Thus it is difficult to see an action such as the instant account deletion happening, as this will mean revenue losses for the company. Players seem to understand that Cipsoft is first and foremost a business enterprise, rather than a moral enterprise, focused on maximizing profit:

I do agree that botters should be punished, but I see where CIP is coming from and not deleting botters outright. It's because botters, like many Tibians, PAY to play the game.

[Character Sikky, 21/05/2009, Post \#23489827]

There is a difficult balance to keep for the company between erasing paying customers who seriously violate the rules and pleasing those who behave according to the rules. The economic side of the problem can however be seen differently according to players posting on the forums, and the company business dilemma (deleting cheaters or pleasing fair players?) can find a good solution with a tough attitude toward cheating:

Well CIP have 2 choices. They can try to stop the botting problem or let it continue to get worse. Letting the problem get worse will also have detrimental affects to CIP's bank balance because people, like me, get fed up of playing a game alongside AI's and abusive people and stop playing. By fighting the botters, sure CIP will lose some customers who cannot bot any longer, but the game will become cleaner and more attractive to new customers, and returning old customers. The loss of cheating players who create a negative atmosphere in Tibia can't be a bad thing in the long 
run, and I honestly feel that the botting over the last years has slowed the growth of Tibia quite significantly in terms of customer growth.

[Character Zaniah, 12/01/2009, Post \#21831916]

In the long run, says this player, acting toward cheating will have positive effects on the company's revenue, entirely based on fair players premium accounts. Cipsoft moral enterprising actions and business interests can therefore go together.

\section{Players as Moral Entrepreneurs}

Tibia players posting on forums did not just observe passively the failure of punishment. They have also been actively trying to encourage reform of the punishment system. This is a major bottom-up contribution in which a number of players are actively trying to shape game rules and their enforcement. In other words, players are here acting as moral entrepreneurs for the game: players act as pressure group promoting reforms in the punishment system that will bring positive results against cheating.

The proposed reforms vary in their nature and some even clash with the company's business strategy. In order to present some of the players' proposals for reforms we use the distinction between retributive and forward looking punishment.

\subsection{Retributive Punishment: Never Give a Second Chance to Botters}

Retributive punishment is backward-looking focusing on past events, with the goal to balance the injustice. There is a sort of vengeance in retributive punishments and this includes making examples of rule violators, so that others will not commit the same rule violation again.

The most common retributive punishments proposed by players on the Tibia forums is account deletion. We already said that players consider the current punishment ( 1 month ban +6 months deletion warning) not sufficient to restore the offence and to prevent the rule violation from being committed again. Instant deletion of a cheating/botting account is seen by players as the best deterrent for discouraging cheating, as Shelbz wrote in the opening message on the aforementioned thread: 
Delete their entire account, regardless of criminal history. No second chances. No refund. [Character Shelbz, 09/01/2009, Post \#17261396]

Deletion of the whole account (and not just of the cheating character ${ }^{27}$ ) is indeed regarded as the most extreme of all punishment for botters in Tibia. Deletion is a retributive punishment as there is no focus on the possible redemption of the offenders, simply wrong-doers are eliminated once and for all from the game. Many posters consider that deletion will allow Cipsoft to prevent the proliferation of bots by making examples, another retributive aspect, as the following message explains:

I have thought the same thing for a long time with deleting botters, giving them a month ban is no better than a slap on the wrist and they go right back at it when the ban is over. Botters need to be deleted to show people what happens when they break the rules!

[Character Landroff, 14/05/2008, Post \#18746059]

Account deletion will therefore have preventive power and restore the function of the social mechanism of punishment against the proliferation of bots:

The instant deletion of an account is a big enough setback that will discourage cheaters from trying again.

[Character Herun the Undead, 07/01/2009, Post \#21775495]

It is important to understand that the current punishment is not only considered too mild, but also something that gives botters more than one chance to get away with their wrong doing. Botters will be banned for 1 month, but after this period they are allowed to keep what they unfairly obtained. Asking for a direct deletion of the whole account implies instead not giving cheaters any second chance and denying any form of forgiveness:

$27 \quad$ A single Tibia account allows the creation of multiple characters. 
Fully endorsing this, we should have harsher punishment on botters and like someone said - to those arguing a "second chance" well that second chance can be making a new account as a clean player.

[Character Nienna Telperin, 15/01/2008, Post \#17326245]

So, it seems that for Tibia players commenting on the forums a strong retributive punishment will allow the company to restore its position as moral enterprise within the community and ensure proper game governance.

A further problem is that game rules are accepted by players when they created their account. Violation of the legal documents is violation of shared rules, and hence an offence toward the social group:

But we all accepted the CipSoft rules when we created our accounts. We accepted to follow them, many players among us is breaking those rules, and what kinda punishment are they getting? A single month banishment. This thread is so correct, breaking the rules = you're gone.

[Character Athanel, 28/02/2008, Post \#17805665]

We see that for this player serious rules violation (i.e. botting) should lead to the deletion of the account (breaking the rules=you're gone). The punishment is considered too lenient for the type of violation, whereas breaking legal documents should lead to important consequences.

Another requested retributive punishment is to take away the advantages unfairly obtained, in particular levels, skills and gold. We already discussed this. Again, this form of punishment is backward looking, because it affects the wrong-doing in itself:

When a botter gets caught, his experience points and skills should be greatly reduced. That would negate the benefits of taking the risk to cheat.

[Character Shelbz, 02/02/2009, Post \#2206153]

We clearly see how this type of punishment (the reduction of unfair advantages) on the one hand is directed toward past achievements with a focus on balancing the offence. On the other side this 
punishment clearly aims to deter botters, given that they will receive a punishment which may prevent the wrong doing from being committed again.

\subsection{Forward Looking Punishments}

Instant deletion of botters accounts, as a punishment, rests on the principle that botters do not deserve a second chance, because of the violation to the legal documents. This punishment is, however, considered sometimes too harsh even for those who have committed the "crime" of botting $^{28}$. Indeed, many in the Tibia community advocate a forward looking attitude and the opportunity to forgive cheaters when they display some will to redeem themselves. Often this second chance is related with a deletion, not of the whole account, but just of the cheating character:

Delete the botted character, bann the account but give them a second chance. I would like to see those who do realise the wrong of what they did be able to play again, play fairly and without cheats.

[Character Spike Narooc, 12/03/2008, Post \#17962662]

Moreover people make mistakes, by being caught botting once, they may decide to stop and realise it is not worth it, however it can be argued that they can have this new chance on a new account [Character Heiti Oblivion, 17/04/2008, Post \#18422677]

As we can see in the above messages giving a second chance to botter is clearly a forward looking attitude, with players (at least those posting on forums) willing to trust that cheaters can redeem themselves and behave according to the legal documents. In addition we find an aversion to harsh punishments such as a reduction of levels. What follows is an answer to a proposal promoting a great reduction of experience, skills and gold of cheaters:

With all due respect I like this idea [of taking away levels and gold] , but I simply think it's too harsh. Sure people have botted but they still should be given a second chance.

28 Crime could be too strong a word for botting. However, often players themselves make analogies between botting and real world crimes such as bank robberies. We use this word consistently in the empirical part of this paper, because that is the terminology used by players and this is in accordance with our analysis approach. 
[Character Blackboom Junklord, 20/04/2009, Post \#23077824] (text in square brackets added)

We clearly see the humanitarian focus of this message contrasting with the proposal to greatly reduce the achievements. Punishment, says this player, should be reasonable so people can realize their mistakes and change how they behave. Punishments which are too harsh do not allow the redemption of cheaters.

A further forward looking punishment is the proposal to make the deletion warning permanent rather than lasting just 6 months. What are the advantages of this type of punishment according to players posting on forums? Clearly this punishment gives a second chance to wrong-doers, because someone will receive the 1 month ban, but after that he/she will have the opportunity to redeem him/herself and play fairly. Any further offence would lead to the deletion of the account:

I suggest that criminal records made by bots should NOT be clean after 6 months, but stays forever, this way the owner of the account could have a second chance so he/she would know that if he/she try to cheat again he/she for sure will lost his account.

[Character Ephius, 12/05/2008, Post \#18727821]

This punishment is forward looking for another reason:

if a botter gets banned for botting, he'll have normal deletion warning like it's now for 6 months \& after it 'clean' criminal list. With the slight difference that the account will have a everlasting deletion warning if it bots again. this way they can get rid of botting without losing their customers.

[Character Hugragra, 02/04/2009, Post \#22822967]

According to players posting on the forums, the permanent warning solution is advantageous for Cipsoft who can tackle cheating without permanently losing customers and revenue. Again, Cipsoft moral enterprising actions and business interests can go together. 


\section{Punishment Reform and Its Outcomes}

On January 212010 a reform of the punishment for violating rule 3c and other offences (such as sharing an account) was announced by Cipsoft (2010b) with an article, entitled Anti-Cheating Measures Reloaded:

\section{Permanent final warnings}

From now on, there will be permanent punishments for all players who gained permanent advantages through the act of cheating which includes the use of unofficial software to play, account sharing and account trading. As many of you have requested in the past, every single account which is identified for having cheated will now get a permanent final warning that does not vanish any more after 6 months. Also, all accounts which currently have a final warning due to the use of unofficial software to play, account sharing or account trading will not lose this warning either. In case of any further rule violation that would lead to a banishment, accounts with a permanent final warning will be automatically deleted without any prior warning.

The punishment reform - so strongly requested by the player community on the forums - took the form of a permanent final warning, following one of the many proposals by players. The final warning simply means that the deletion warning, given as a punishment (together with the 1 month ban), rather than just remaining for 6 months, will last forever. In this way any further violation of rules will lead to full deletion of the account. This of course implies that other players' proposals for punishment reform have not been implemented and in particular the instant deletion of cheaters accounts and the reduction of advantages obtained by botting. With the final warning, however, deletion of an account becomes the punishment for every second offence. This reform of the punishment system was warmly welcomed by many Tibia players posting on the forums as a step toward solving the botting problem:

A step in the right direction. The permanent final warning is an awesome idea, the best way to prevent rule violations is to make the penalty harsh enough to outweigh the benefits of cheating [Character Dylen Lord of Chaos, 26/01/2010, Post \#26324440] 
In this message the final warning is presented as having a preventive power that outweighs the advantages of cheating. Interestingly, the permanent final warning also applied to accounts that were on temporary warning when the reform was introduced. This has been described by players as unfair and against the principle of Ex Post Facto Law:

There is a very simple principle of criminal Law, as far as I know, common to all legal democratic systems: the Law may not retroact to harm, to jeopardize. The cheating was perfomed under some applicable rules. Only these rules should apply and not other rules created after the cheating.

[Character, Dark Harlequin, 22/01/2010, Post \#26275106]

The new rules are applied retroactively to past behaviours (all accounts which currently have a final warning [...] will not lose this warning either) and those with a 6 months temporary warning at the time when the reform was introduced received a permanent warning (see figure 1 for a description). For this forum poster (but others expressed this same concern on the forum), this contrasts with the 'real world' legal principle that people can only be punished according to laws existing at the time when the rule violation was committed. There are different problems related with this.

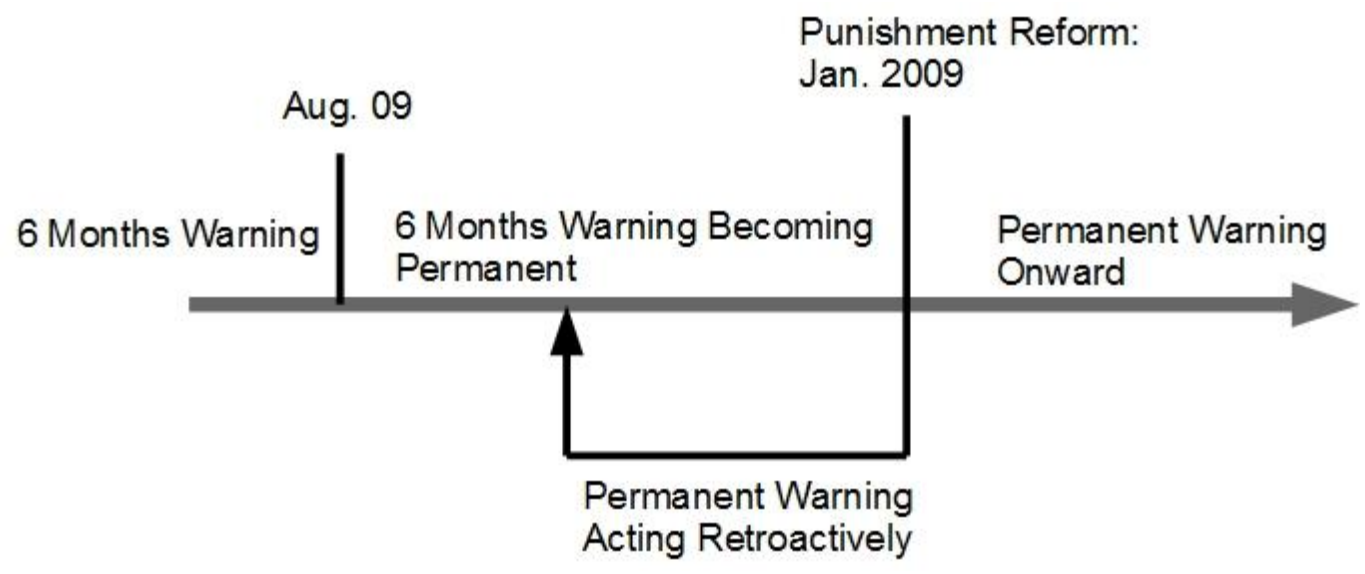

Figure 1. Permanent Warning Acting Retroactively

First, we are in a situation in which someone is punished with different rules compared to those he/she was playing under when the rule violation occurred. Here a further analogy with 'the real world' is made by a forum poster: 
I don't mind ppl who get banned from now on get a permanent deletion warning but changing old deletion warnings in permanent one is like arresting a guy for theft, then once he's in jail already you change the rule for theft to lifetime penalty. People commit violations based on the assumptions they have about what the penalty would be. They cheated knowing what would be the penalty is they did it, then after doing it, suddenly their penalty changed? That's just unjustice lol. [Character Camahimos, 21/01/2010, Post \#26266204]

According to this player, people commit rule violations by evaluating the cost/benefits in relation to penalties existing at the time of the wrong-doing. Although this assumption could be criticized as utilitarian, what this player is conveying is the idea that players may evaluate penalties before violating rules. In this case, the violation (i.e. using a bot) was committed with the 6 months warning as penalty, but afterwards the punishment became a permanent warning in a situation in which the new penalty could not be evaluated beforehand by rule violators. However, and secondly, this utilitarian attitude toward an evaluation of punishments is not accepted by everyone in the community:

Although I loathe comparing rule enforcement in Tibia to real life criminal justice systems I will simply point out that in the case of a state changing minimum sentences for crimes, appeals can and are raised to ensure that previously convicted felons have their sentences reviewed to comply with the updated policy. As for logic, it seems quite logical that everyone who has been recently been punished for cheating is not given the chance to freely reap the benefits of their cheating simply because they have only now decided the costs outweigh the benefits.

[Gamemaster Lycant, 22/01/2010, Post \#26276564]

Even if laws act retroactively this is justified for some players. Using a bot is a severe offence - in a game context - and it is acceptable therefore for many players that in an MMORPG "crimes" can be redefined and "criminals" can receive new punishments which are deemed proportional to their wrong doing. Finally, it is important to disclose that some players felt that the moral enterprise has the right to act as full dictator of the game and has therefore the right to change the rules to meet its need: 
Anyone posting here has an account, which means they agreed to CIP's terms to be full dictators here. They preserve the right to delete/abuse/reset/do anything to your account at all times.

[Character Elaynda, 26/01/2010, Post \#26321198]

In fact, says this player, when one creates an account and accepts the rules he/she also accepts that Cipsoft has the right to change the rules at its discretion. The Tibia Extended Service Agreement (Cipsoft, 2010c) clearly states that "CipSoft $\mathrm{GmbH}$ reserves the right to partially or completely modify this agreement at any time". For this reason, the comparison with real law could be irrelevant for legal scholars, but it is not for players who seem to use the comparison between real and virtual law to persuade their peers about the unfairness of this decision. However, the legal documents legitimize Cipsoft's actions in this case. Even though having a law that applies retroactively does not seem fair, especially when compared to real life law, virtual worlds are different. In virtual worlds, authority (the game company) can exercise absolute power (Castronova, 2005) based on legal documents and control of the game code (Humpreys, 2008) and hence game companies are in a position to allow the "game law" to act retroactively whenever they want.

\section{Conclusion: Towards the design of appropriate Punishment Systems in Virtual Worlds}

Botting is a practice in online games which is expressly forbidden by EULAs and other documents, documents which are called 'legal' and serve to 'govern' the relationship between players and the game. This paper is grounded in a sociological analysis of player practices and discourses surrounding the use of bots and the development of appropriate punishments for such rule violation in MMORPGs. We are concerned with explaining how, in these online worlds, rules and the enforcement of punishments for their violations emerge and change over time in response to deviant behaviours. We are interested in particular in exploring the guiding principles underlying punishment systems in MMORPGs.

In our case study of Tibia we found a dialectic confrontation between Cipsoft and some Tibia players (those actively posting on the game forums) in relation to the issue of sufficient and 
appropriate punishments for the use of bots in Tibia. The company's failure to sufficiently punish and deter a number of players from botting appeared to weaken the company's position and reputation as what Becker (1963) would call a 'moral enterprise'. However, there was a clear conflict for the company between being an economic enterprise with no desire to delete paying customers and the company role as moral enterprise focused on ensuring a fair service for all the players. In this case study certain players posted their critical comments on official and unofficial forums and threatened to withdraw payment in order to pressurise Cipsoft to reform the punishment system. In this way, players also acted as moral entrepreneurs for the game, suggesting alternative strategies and reforms to the punishment system and giving reasons for these proposed alternatives. Players posting on forums also expressed the idea that the company moral enterprising initiatives and business interests should go together.

De Zwart (2009) has argued that there is often a lack of transparency regarding the values sought to be protected and promoted by the platform providers in MMORPGs. The guiding principle of Tibia's punishments for botting appears to be to maintain 'fairness' in the game world while sustaining the game company's reputation and game revenues. However, the Tibia punishment system bans cheaters but does not attempt to rebalance the inequalities caused by rule violations (i.e. be retributive) and there is more interest, from the company point of view, with rehabilitating cheaters as paying customers (i.e. be forward looking). This does not appear to be 'fair' or 'just' in the way that Humpreys (2008) has called for, especially for fair players who always behave according to the game rules.

Indeed, for Beccaria (1764) a punishment, in order to be effective, requires the privation of the advantages obtained by violating the rules. Current punishments in most MMORPGs do not consider this option. Punishments, or penalties as they are often called in MMORPGs policy documents, are mostly based on external punishments such as bans (or suspensions) and deletion after multiple severe violations of rules (see for instance $\mathrm{WoW}^{29}$ or Eve Online ${ }^{30}$ among others). In Tibia, the exclusive use of mild external punishment was one of the sources of the failure of punishment. These external punishments are not retributive ${ }^{31}$ and do not directly affect what has

\footnotetext{
http://www.wow-europe.com/en/policy/accountpenalties.html

http://www.eveonline.com/pnp/banning.asp

Except deletion which happens only after multiple severe violations and against the company's will to act inclusively.
} 
been unfairly obtained (e.g. levels or gold) internally in the game world. In the case of Tibia we have seen how players often use analogies with the real world in order to describe how leaving unfair advantages with botters is unfair. While not all comparisons between behaviours in real and online environments are appropriate, affecting unfair advantages in-game should, and could, be a key aspect of anti-cheating actions, while retaining the unique aspects of the virtual space. Our recommendation for MMORPGs governance design is that developers and game builders should consider the ethical principles underpinning their punishment systems and aim to balance the offence caused by severe rules violation with respect for the consumer and personal rights of all game players.

Our findings on the ethical implications of different punishment systems have relevance for the design of governance systems and information security in online worlds more generally (Braman and Malaby, 2006). In particular our approach counters the dominant approach to information security research for Virtual Worlds as contained in the current European Research Programme and publications by the European Network of Information Security Agency (ENISA). While a recent ENISA paper argues that game providers, should "create an appropriate balance between security measures aimed at detection and those aimed at prevention" (2008, p. 54) they focus only on technical security measures and do not consider the potential offered by social control, or a combination of social and technical measures, for either detection or prevention of cheating. Our work shows that there are options other than exclusively technical information security measures to counteract cheating in MMOPRGs. In our view there are many problems that technical security mechanisms do not solve or if they do solve them, they do so in a manner which is inappropriate in terms of the online context and require the player to surrender too much control. We argue therefore that information security research should more generally explore and foster the adoption of social mechanisms to prevent and counteract cheating and other security threats in Virtual Worlds.

\section{References}

Achterbosch, L., Pierce, R., and Simmons, G. (2008). Massively multiplayer online role-playing games: the past, present,and future. Comput. Entertain., 5(4), 1-33. 
Alemi, F. (2007). An Avatar's Day in Court: A Proposal for Obtaining Relief and Resolving Disputes in Virtual World Games. UCLA Journal of Law \& Technology, 11(2), http://www.lawtechjournal.com/articles/2007/06_080130_alemi.php. Accessed 14 July 2010.

Bainbridge, W. S. (2010). The Warcraft Civilization. Cambridge MA: MIT Press.

Beccaria, C. (1764 Trans. 1819). On Crimes and Punishments.

http://www.constitution.org/cb/crim_pun.htm. Accessed 20 May 2010.

Becker, H. (1963). Outsiders: Studies in the Sociology of Deviance. New York: The Free Press.

Bedau, H. A. and Kelly, E. (2005). Punishment. In Stanford Encyclopedia of Philosophy, http://plato.stanford.edu/entries/punishment/. Accessed 29 November 2010.

Bijker, W. E. (1995). Of Bicycles, Bakelites, and Bulbs. Cambridge MA: MIT Press.

Blizzard Entertainment. 2010. World of Warcraft End User License Agreement. http://www.worldofwarcraft.com/legal/eula.html. Accessed 20 October 2010.

Braman, S. and Malaby, T. M., (2006). Preface. First Monday, special issue number 7 (September 2006), http://firstmonday.org/issues/special11_9/preface/index.html. Accessed 22 January 2011.

Callon, M. (1986). Some elements of a sociology of translation: Domestication of the scallops and the fishermen of St Brieuc Bay. In J. Law (Ed.) Power, action and belief: A New Sociology of Knowledge (pp. 196-233). London: Routledge \& Kegan Paul.

Castronova, E. (2005). Synthetic worlds: The Business and Pleasure of Gaming. Chicago: Chicago University Press.

Charmaz, K. (2006). Constructing grounded theory. Thousand Oaks: Sage Publications.

Cipsoft. (1997-2010). Tibia. http://www.tibia.com

Cipsoft. (2009a). Where Will Cheaters Go From Here?. http://www.tibia.com/news/?subtopic=latestnews\&id=910. Accessed 1 June 2010.

Cipsoft. (2009b). Tibia Rules. http://www.tibia.com/support/?subtopic=tibiarules. Accessed 1 June 2010.

Cipsoft. (2010a). Tibia Manual. http://www.tibia.com/gameguides/?subtopic=manual. Accessed 1 June 2010.

Cipsoft. (2010b). Anti Cheating Measures Reloaded,

http://www.tibia.com/news/?subtopic=newsarchive\&id=1207\&fbegind=23\&fbeginm=12\&fbeginy $=2009 \&$ fendd $=22 \&$ fendm=1\&fendy=2010\&flist=11111111. Accessed 1 June 2010.

Cipsoft (2010c). Tibia Extended Service Agreement,

http://www.tibia.com/support/?subtopic=legaldocuments\&page=extendedagreement. Accessed 02 September 2011.

Cragg, W. (1992). The Practice of Punishment: Toward a Theory of Restorative Justice.

London: Routledge.

Consalvo, M. (2007). Cheating: Gaining advantage in videogames. Cambridge, MA.: MIT Press.

Consalvo, M. (2009). There is No Magic Circle. Games and Culture 4(4), 408-417.

DeKoven, B. (1978). The Well-Played Game. New York: Doubleday.

de Zwart, M. (2009). Piracy Vs. Control: Models of Virtual World Governance and Their Impact on Player and User Experience. Journal of Virtual Worlds Research, 2(3), https://journals.tdl.org/jvwr/article/view/663/511. Accessed 16 June 2011. 
Di Chen, B. and Maheswaran, M. (2004). A fair synchronization protocol with cheat proofing for decentralized online multiplayer games. In Proceedings. Third IEEE International Symposium on Network Computing and Applications, 2004. (NCA 2004), 372- 375.

European Network of Information Security Agency. (2008). Virtual worlds, real money security and privacy in massively-multiplayer online games and social and corporate virtual worlds. ENISA Position Paper. http://www.enisa.europa.eu/pages/02_01_press_2008 11_20_online gaming.html Accessed 1 June 2010.

Ess, C and AoIR. (2002). Ethical decision-making and Internet research. http://aoir.org/reports/ethics.pdf. Accessed 4 March 2009.

Ferretti, S. and Roccetti, M. (2006). AC/DC: an algorithm for cheating detection by cheating. In Proceedings of the 2006 international Workshop on Network and Operating Systems Support For Digital Audio and Video (NOSSDAV '06). ACM, New York, NY, pp. 1-6.

Fields, D.A. and Kafai, Y.B. (2009). Cheating in virtual worlds: transgressive designs for learning. On the Horizon, 17(1), 1-20.

Foucault, M. (1975). Discipline and Punish: the Birth of the Prison. London: Penguin.

Hine, C. (2000). Virtual Ethnography. London: Sage Publications

Hoglund, G. and McGraw, G. (2008). Exploiting Online Games: Cheating Massively Distributed Systems. First Addison-Wesley Professional.

Humphreys, S. (2008). Ruling the virtual world: Governance in massively multiplayer online games. European Journal of Cultural Studies, 11(2), 149-171.

Johansson, M. (2009). Why unreal punishment in response to unreal crimes might actually be a really good thing. Ethics and Information Technology, 11(1), 71-79.

Kerr, A. (2006). The business and culture of digital games: gamework/gameplay. London: Sage.

Kimppa, K. and Bissett, A.(2005). The ethical significance of cheating in online computer games. International Review of Information Ethics, 4, 31-38.

Kücklich, J. (2007). Homo Deludens - Cheating as a methodological tool in digital games research. Convergence, 13(4), 355-367.

Kücklich, J. (2009). A Techno-Semiotic Approach to Cheating in Computer Games: Or How I Learned How to Stop Worrying and Love the Machine. Games and Culture, 4(2), 158169.

Latour, B. (1988). The princes for machines as well as for machinations. In B. Elliott (Ed.) Technology and Social Process (pp. 20-43). Edinburgh University Press: Edinburgh.

Latour, B. (2005). Reassembling the Social: An Introduction to Actor-Network Theory. Oxford: Oxford University Press.

MacKenzie, D. and Wajcman, J. (Eds.). (1999). The Social Shaping of Technology (2nd Edition). Buckingham: Open University Press.

Morrison, B. (2009). The Game Design Canvas: Punishment and Rewards Systems. http://thegameprodigy.com/the-game-design-canvas-punishment-and-reward-systems/. Accessed 22 January 2011.

Nardi, B. (2010). My Life as a Night Elf Priest. An Antropological Account of World of Warcraft. Ann Arbor: The University of Michigan Press. 
Rousseau, J. J. (1762). The Social Contract. Available at http://www.constitution.org/jjr/socon.htm. Accessed 10 October 2010.

Salen, K. and Zimmerman, E. (2004). Rules of Play: Game design Fundamentals. Cambridge MA: The MIT Press.

Sicart, M. (2009). The Ethics of Computer Games. Cambridge: The MIT Press.

Smed, J. and Hakkonen, H. (2006). Algorithms and Networking for Computer Games. Chichester: John Wiley \& Sons.

Smith, J. H.( 2004). Playing Dirty - Understanding Conflicts in Multiplayer Games. 5th Annual Conference of The Association of Internet Researchers. The University of Sussex, 19-22 September, http://jonassmith.dk/weblog/uploads/playing_dirty.pdf. Accessed 15 July 2010.

Strauss, A. and Corbin, J. (1998). Basics of Qualitative Research: Techniques and Procedures for Developing Grounded Theory. (2nd Edition) Thousand Oaks, CA: Sage.

Taylor, T. L. (2006). Play Between Worlds: Exploring Online Game Culture. Cambridge, MA: The MIT Press.

Yan, J. and Choi, H. J. (2002). Security Issues in Online Games. The Electronic Library, 20(2), 125-133.

Yan, J. Y. and Randell, B. (2005). A systematic classification of cheating in online games. In Proceedings of 4th ACM SIGCOMM Workshop on Network and System Support For Games. New York, NY: ACM, 1-9.

Wikipedia contributors. 2010. MMORPG bots. Wikipedia, The Free Encyclopedia, http://en. wikipedia.org/w/index.php?title=MMORPG bots\&oldid=363989084. Accessed 29 November 2010.

Withson, J. R.( 2010). Rule Making and Rule Breaking: Game Development and the Governance of Emergent Behaviour. FibreCulture Journal, Issue 16, http://sixteen.fibreculturejournal.org/rulemaking-and-rule-breaking-game-development-and-the-governance-of-emergent-behaviour/. Accessed 15 October 2010. 